\title{
Interim-Response-Adapted Therapy in Advanced Hodgkin's Lymphoma: Current Status
}

It has been 6 years after our initial publication of a phase II trial of response-adapted therapy (RAT) in advanced Hodgkin's lymphoma (aHL), which was one of the first prospective studies published using RAT in aHL. ${ }^{[1]}$ We had treated patients with aHL (defined as Stage IIB, III, and IV) with two cycles of ABVD and then performed an interim positron emission tomography/ computed tomography (iPET-CT) scan iPET2. Those who had a Deauville score (DS) of 4 or 5 received four cycles of escalated BEACOPP (EB) and those with DS 1-3 continued 4 more ABVD. The disease-free survival (DFS) at 2 years was $76 \%$, and overall survival (OS) was $88 \%$. With more mature follow-up, the DFS at 5 years was $77 \%$, and OS was $85 \%$ for the entire cohort of 50 patients. ${ }^{[2]}$ The survival was inferior among iPET2+ (5-year DFS [50\%] and OS [62\%]) versus iPET2--ve patients (5-year DFS [82\%] and OS [85\%]). These results have been replicated in much larger multicenter studies globally, and RAT has been accepted as one of the standard modes of treatment in aHL.

\section{Context of the Study Scenario in 2010-2011}

PET-CT scanning was available at the Cancer Institute from 2007. However, this was used only for staging and end therapy assessment and not for treatment tailoring. The Indian data ${ }^{[3]}$ suggested that only about $70 \%$ of patients with aHL were cured with ABVD, and we needed to do better. Strong data favored the use of EB (GHSG HD9 study), ${ }^{[4]}$ but the toxicities were a concern. We needed some way to identify those who would "fail" ABVD. The International Prognostic Scoring System had significant limitations in identifying "high risk" subsets. Emerging data suggested that iPET2 could identify a "very high risk" subset and also the possibility of adapting therapy based on iPET2. ${ }^{[5,6]}$ On this background, the iPET2-adapted study was designed.

\section{Study Design and Other Challenges}

How to interpret the interim positron emission tomography 2 ?

The prognostic value of iPET 2 was known, but the challenge was to have a standard definition of what was positive and negative. This was discussed worldwide, and the recommendations of the International Harmonization Project were published. ${ }^{[7,8]}$ Although the term "DS" was not yet popular, we had a guideline which was easy to use and reproducible and appropriate for a clinical trial situation.

\section{Can we deliver escalated BEACOPP safely?}

The original HD9 trial had reported a significant increase in toxic deaths with the use of EB. ${ }^{[4]}$ Based on our discussions with the authors of GHSG HD9, we incorporated the following safeguards while delivering EB: routine use of G-CSF from day 9 and prophylactic antibiotics. Initially, all patients requiring EB were treated as inpatients till the recovery of counts. Later with more experience, some patients were treated as outpatients. Although half our patients developed febrile neutropenia, there were no toxic deaths in our study.

\section{How to fund the delivery of escalated BEACOPP?}

The cost of chemotherapy in EB is almost similar to ABVD as traditional agents with available generics are used. However, the cost of supportive care (antibiotics, inpatient care, and growth factors) is higher because febrile neutropenia occurs in half the patients. This is a concern in private practice when patients are paying out of pocket.

Study design, sample size, and enrolment

Large sample sizes are a challenge in single-center studies. We calculated the sample size for the entire group of patients instead of only for the PET positive cohort. By aiming for a DFS of $85 \%$ for the group as a whole, we estimated a sample size of 50 for a power or $80 \%$ with $5 \%$ alpha. As EB had already demonstrated a DFS of $85 \%$, we felt that anything lower than $85 \%$ would be unacceptable.

\section{Response-Adapted Therapy in Advanced Hodgkin's Lymphoma - What Have we Learnt?}

Since the publication of our study, several large trials [Table 1] have been published which have looked at iPET2-guided therapy in aHL. There are two approaches in RAT:

i. Start with ABVD and then tailor therapy based on iPET2 ("Chronos") or

ii. Start with EB and then tailor therapy based on iPET2 ("Kairos").

The following can be inferred from the available studies:

- DS is simple and it works

- DS had good reproducibility, acceptable interobserver variability and is easy to interpret making it a practical tool for routine patient care

- Positive iPET (DS 4,5) after 2 cycles is seen in $10 \%-20 \%$ of patients after 2 cycles

- Therapy escalation improves the outcomes of iPET2+ve patients 


\begin{tabular}{|c|c|c|c|c|c|c|}
\hline \multirow{3}{*}{$\overline{\text { Study }}$} & \multirow{3}{*}{ Phase } & \multirow{3}{*}{ Initial Rx } & \multirow{3}{*}{ Approach after iPET2 } & \multirow{2}{*}{\multicolumn{2}{|c|}{5 years-DFS/EFS/PFS }} & \multirow{3}{*}{ Remarks } \\
\hline & & & & & & \\
\hline & & & & $\begin{array}{c}\text { iPET2 } \\
\text { negative, } \%\end{array}$ & $\begin{array}{c}\text { iPET } \\
\text { positive, } \%\end{array}$ & \\
\hline$\overline{\text { Press } \text { et al. } .^{[9,10]}}$ & \multirow[t]{2}{*}{2} & \multirow[t]{2}{*}{ ABVDX2 } & Positive: EBX4 & 76 & 66 & \multirow{2}{*}{$\begin{array}{l}25 \% \text { of PET negative patients } \\
\text { relapsed }\end{array}$} \\
\hline SWOG S0816 & & & Negative: ABVDX4 & & & \\
\hline Johnson et al. ${ }^{[11,12]}$ & \multirow[t]{2}{*}{3} & \multirow[t]{2}{*}{ ABVDX2 } & Positive: EBX4 or SB14 X4 & 83 & 66 & \multirow{2}{*}{$\begin{array}{l}\text { Deescalation to AVD in PET2 } \\
\text { negative was noninferior }\end{array}$} \\
\hline RATHL-CRUK/07/033 & & & Negative: AVD versus ABVD & & & \\
\hline Gallamini et al..$^{[13]}$ & \multirow[t]{2}{*}{3} & \multirow[t]{2}{*}{ ABVDX2 } & Positive: EB versus R-EB & 87 (3 years) & 60 (3 years) & \multirow{2}{*}{$\begin{array}{l}\text { Radiotherapy did not impact those } \\
\text { who had bulky but were PET } \\
\text { negative }\end{array}$} \\
\hline GITIL/FIL HD0607 & & & Negative: ABVDX4 & & & \\
\hline Borchmann et al..$^{[14]}$ & \multirow[t]{2}{*}{3} & \multirow[t]{2}{*}{$\mathrm{EBX} 2$} & Positive: $6 \mathrm{XEB}$ or R-EB & 91 & 88 & \multirow{2}{*}{$\begin{array}{l}48 \% \text { were PET } 2 \text { positive did not } \\
\text { use DS. iPET2+: No impact on } \\
\text { outcome }\end{array}$} \\
\hline HD18-GHSG & & & $\begin{array}{l}\text { Negative: } 4 \text { XEB versus } \\
6 \text { XEB }\end{array}$ & & & \\
\hline \multirow{2}{*}{$\begin{array}{l}\text { Zinzani et } \\
\text { HD0801 }\end{array}$} & \multirow[t]{2}{*}{2} & \multirow[t]{2}{*}{ ABVDX2 } & $\begin{array}{l}\text { Positive: Salvage IGEV f/b } \\
\text { HDT }\end{array}$ & 81 (2 years) & 76 (2 years) & \multirow[t]{2}{*}{$\begin{array}{l}\text { 20/103 patients did not undergo } \\
\text { ASCT and received only ABVD }\end{array}$} \\
\hline & & & Negative: ABVD & & & \\
\hline Casasnovas et al..$^{[16]}$ & 3 & EBX2 & Positive: Continue EB & 88 & 68 & $84 \%$ were eligible for deescalation \\
\hline \multicolumn{3}{|l|}{ AHL2011-LYSA } & \multicolumn{3}{|l|}{ Negative: ABVD versus EB } & \\
\hline
\end{tabular}

- Escalated therapy in iPET2 + patients yielded better results $(50 \%-68 \%$ 5-year event-free survival [EFS]) than those reported historically with continued ABVD $(<20 \%$ 5-year EFS)

- "Kairos approach" seems to be having better EFS (90\%-95\%) than "chronos" approach (80\%-85\%) (Caveat: this conclusion is based on cross-trial comparisons)

- Starting with EB in AHLL trial seemed to reduce the PET2 + vity rates $(12 \%)$

- Overall outcomes seem to be better than those seen with escalation trials ${ }^{[16]}$

- Deescalation to AVD in iPET2 negative reduces the risk of bleomycin toxicity

- Deescalation to AVD was noninferior to the continuation of ABVD in iPET-2 negative patients in the RATHL study this was a significant finding which when applied to clinical practice reduces the risk of fatal bleomycin lung toxicity.

\section{Limitations of Response-Adapted Therapy}

The original retrospective data with iPET2 showed a very strong negative predictive value for a negative scan with these patients enjoying the survival of $90 \%-95 \% .^{[5,17]}$ Unfortunately, in all prospective studies starting with ABVD, the survival in the PET2-ve has been more modest (76\%-87\%). Although RAT (therapy escalation) does improve the survival in PET-2+ve patients (compared to continued ABVD), there are two key limitations:

i. A subgroup of patients $(15 \%-20 \%)$ who fail therapy despite having negative iPET2. We need better markers to identify the poor risk subsets even among those who are iPET2-ve ii. Outcome of iPET2+ve patients, even after escalation, is only $50 \%-60 \%$ (EFS) and needs to improve further. We need better interventions than EB in these patients.

Tools for better identification of the poor risk groups

The International Prognostic Score has limited ability in identifying the subsets of patients who have the survival of $<50 \%-60 \%$ in the modern era. There are some data to suggest that CD68 expression and patterns of PD-1 expression can predict for inferior survival even among PET-ve patients. ${ }^{[18]}$ These biomarkers needs to be refined further to identify the "poor" subsets among iPET2-ve. Interestingly, in studies which used EB upfront (the "Kairos" approach), EFS was 88\%-91\%, which (keeping all the caveats of cross-trial comparisons) does seem better than that achieved with ABVD followed by escalation (the "chronos" approach). ${ }^{[14,16]}$

Better therapy for the interim positron emission tomography 2 positive patients

The study which used autotransplant as consolidation (instead of BEACOPP) reported a survival of $76 \%$ in iPET2+ve patients, which is the highest reported so far. ${ }^{[15]}$ The HD18 trial showed excellent survival even among PET2+ve patients, but the methodology used to define positivity was not standard (DS was not used). Nearly half patients in HD18 had positive iPET2 (compared to $12 \%$ in the AHL2011 study which also started with 2 EB). Incorporation of nivolumab or brentuximab may improve the survival in this subset, but at present, data are lacking. 


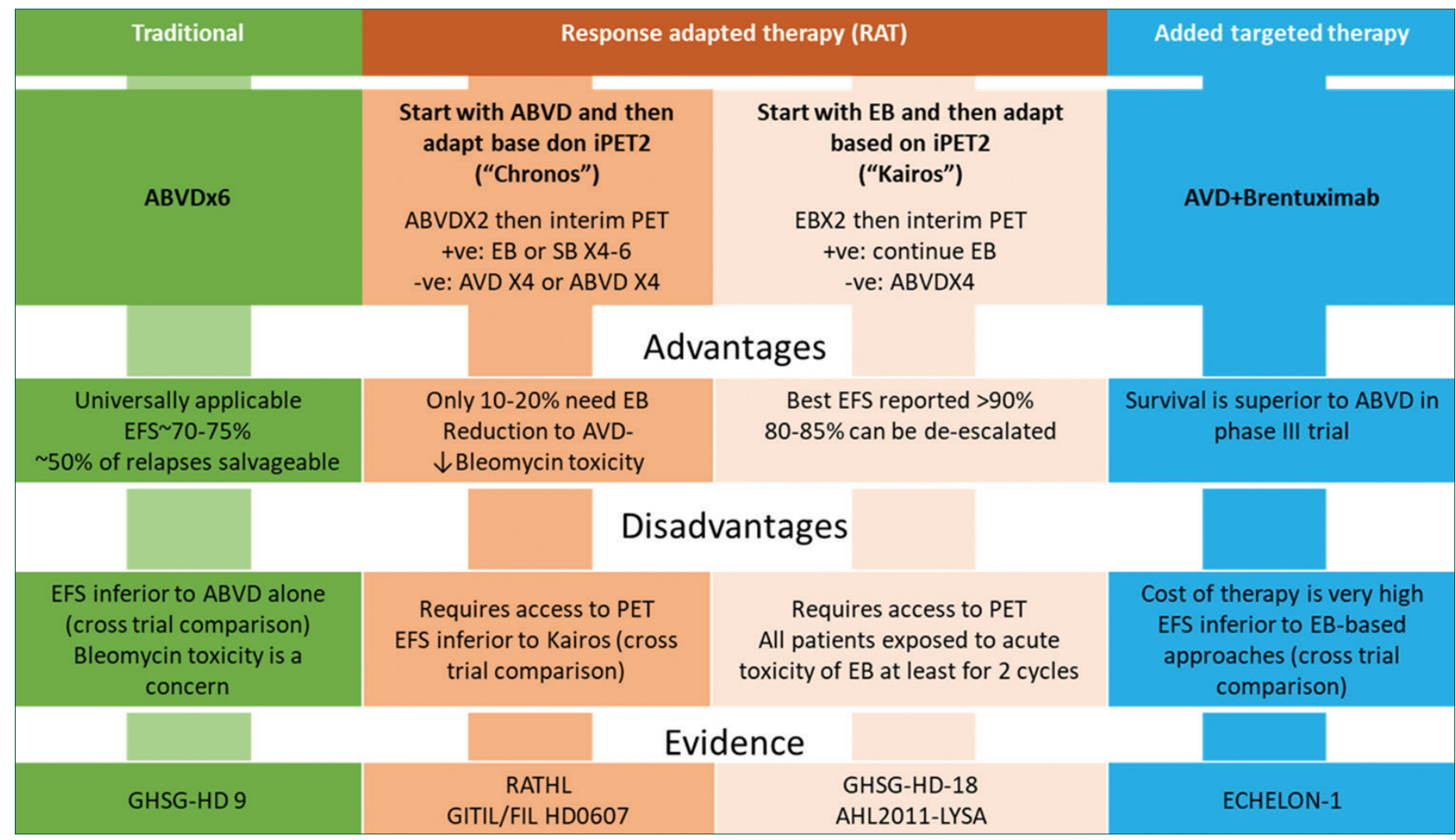

Figure 1: Summary of current approaches to treatment of Hodgkin's lymphoma

Response-Adapted Therapy with the "Chronos" Approach May Be an Optimal Approach for Indian Patients Who Have Access to Positron Emission Tomography-Computed Tomography

Current standard treatment approaches for aHL are summarized in Figure 1. Among these, RAT is a useful "middle path," which is suitable for use in our context, provided one has access to PET-CT scans.

Compared to earlier data from the Indian centers (5-year EFS of $70 \%-75 \%$ with ABVD X6), RAT produces the survival of about $80 \%-85 \%$ which is an improvement. ${ }^{[1-3,19]}$ An important caveat here is the effect of "stage migration" when we are comparing patients staged by CT scans versus patients staged by PET-CT.

An additional advantage of the PET-guided therapy is the option for deescalation to AVD based on the RATHL results in iPET2-ve patients. In fact, the removal of bleomycin in cycles 3-6 has nearly eliminated deaths due to bleomycin pulmonary toxicity in aHL patients.

BEACOPP toxicity is a challenge in the Indian context where we have to deal with patients from the poor economic and social backgrounds. Patients have to understand the importance of reporting on time when they develop febrile neutropenia. Moreover, hospitals have significant space constraints and may not be able to admit these patients when required. If these aspects can be taken care, EB can be delivered in India as demonstrated by our study. Because of these reasons, the "Kairos" approach may not be feasible in India where all patients would receive at least two cycles of EB.

If one wants to try the "chronos" model but is unable to deliver EB, one option is to use 4-6 cycles of BEACOPP-14 in iPET2+ve patients. This is much less toxic and can be easily delivered without requirement for admissions. BEACOPP-14 was found as effective as EB (non-randomized comparison) in the RATHL study. ${ }^{[1]}$ Recent reports from a multicenter analysis have shown that RAT can be safely practiced in the Indian conditions. ${ }^{[20]}$

Prasanth Ganesan

Department of Medical Oncology, Jawaharlal Institute of Postgraduate Medical Education and Research, Puducherry, India

Address for correspondence: Dr. Prasanth Ganesan,

Department of Medical Oncology, Jawaharlal Institute of Postgraduate Medical Education and Research, Puducherry - 605 006, India. E-mail:p.ganesan@jipmer.edu.in

Submitted: 28-Dec-2019 Revised: 02-Jan-2020 Accepted: 06-Jan-2020 Published: 17-Feb-2020

\section{References}

1. Ganesan P, Rajendranath R, Kannan K, Radhakrishnan V, Ganesan TS, Udupa K, et al. Phase II study of interim PET-CT-guided response-adapted therapy in advanced Hodgkin's lymphoma. Ann Oncol 2015;26:1170-4.

2. Ganesan P, Sagar T, Radhakrishnan V, Dhanushkodi M. 
Response-adapted therapy in Hodgkin's lymphoma: Long-term follow up of a phase II clinical trial. Clin Lymphoma Myeloma Leuk 2018;18:S231.

3. Ganesan P, Kumar L, Raina V, Sharma A, Bakhshi S, Sreenivas V, et al. Hodgkin's lymphoma-long-term outcome: An experience from a tertiary care cancer center in North India. Ann Hematol 2011;90:1153-60.

4. Diehl V, Franklin J, Pfreundschuh M, Lathan B, Paulus U, Hasenclever D, et al. Standard and increased-dose BEACOPP chemotherapy compared with COPP-ABVD for advanced Hodgkin's disease. N Engl J Med 2003;348:2386-95.

5. Gallamini A, Hutchings M, Rigacci L, Specht L, Merli F, Hansen M, et al. Early interim 2-[18F] fluoro-2-deoxy-D-glucose positron emission tomography is prognostically superior to international prognostic score in advanced-stage Hodgkin's lymphoma: A report from a joint Italian-Danish study. J Clin Oncol 2007;25:3746-52.

6. Gallamini A, Patti C, Viviani S, Rossi A, Fiore F, Di Raimondo F, et al. Early chemotherapy intensification with BEACOPP in advanced-stage Hodgkin lymphoma patients with a interim-PET positive after two ABVD courses. Br J Haematol 2011;152:551-60.

7. Gallamini A, Fiore F, Sorasio R, Meignan M. Interim positron emission tomography scan in Hodgkin lymphoma: Definitions, interpretation rules, and clinical validation. Leuk Lymphoma 2009;50:1761-4.

8. Meignan M, Gallamini A, Meignan M, Gallamini A, Haioun C. Report on the first international workshop on interim-PET-scan in lymphoma. Leuk Lymphoma 2009;50:1257-60.

9. Press OW, Li H, Schöder H, Straus DJ, Moskowitz CH, LeBlanc M, et al. US intergroup trial of response-adapted therapy for stage III to IV Hodgkin lymphoma using early interim fluorodeoxyglucose-positron emission tomography imaging: Southwest oncology group S0816. J Clin Oncol 2016;34:2020-7.

10. Stephens DM, Li H, Schöder H, Straus DJ, Moskowitz CH, LeBlanc M, et al. Five-year follow-up of SWOG S0816: Limitations and values of a PET-adapted approach with stage III/ IV Hodgkin lymphoma. Blood 2019;134:1238-46.

11. Johnson P, Federico M, Kirkwood A, Fosså A, Berkahn L, Carella A, et al. Adapted treatment guided by interim PET-CT scan in advanced Hodgkin's lymphoma. N Engl J Med 2016;374:2419-29.

12. Rotman J, Fossa A, Federico M. Response-adjusted therapy for advanced Hodgkin lymphoma (RATHL) trial: Longer follow up confirms efficacy of de-escalation after a negative interim pet scan (CRUK/07/033). Hematol Oncol 2017;35:65-7.

13. Gallamini A, Tarella C, Viviani S, Rossi A, Patti C, Mulé A, et al. Early chemotherapy intensification with escalated BEACOPP in patients with advanced-stage Hodgkin lymphoma with a positive interim positron emission tomography/computed tomography scan after two ABVD cycles: Long-term results of the GITIL/ FIL HD 0607 trial. J Clin Oncol 2018;36:454-62.
14. Borchmann P, Goergen H, Kobe C, Lohri A, Greil R, Eichenauer DA, et al. PET-guided treatment in patients with advanced-stage Hodgkin's lymphoma (HD18): Final results of an open-label, international, randomised phase 3 trial by the German Hodgkin Study Group. Lancet 2018;390:2790-802.

15. Zinzani PL, Broccoli A, Gioia DM, Castagnoli A, Ciccone G, Evangelista $\mathrm{A}$, et al. Interim positron emission tomography response-adapted therapy in advanced-stage Hodgkin lymphoma: Final results of the phase II part of the HD0801 study. J Clin Oncol 2016;34:1376-85.

16. Casasnovas RO, Bouabdallah R, Brice P, Lazarovici J, Ghesquieres H, Stamatoullas A, et al. PET-adapted treatment for newly diagnosed advanced Hodgkin lymphoma (AHL2011): A randomised, multicentre, non-inferiority, phase 3 study. Lancet Oncol 2019;20:202-15.

17. Gallamini A, Barrington SF, Biggi A, Chauvie S, Kostakoglu L, Gregianin $\mathrm{M}$, et al. The predictive role of interim positron emission tomography for Hodgkin lymphoma treatment outcome is confirmed using the interpretation criteria of the Deauville five-point scale. Haematologica 2014;99:1107-13.

18. Agostinelli C, Gallamini A, Stracqualursi L, Agati P, Tripodo C, Fuligni $\mathrm{F}$, et al. The combined role of biomarkers and interim PET scan in prediction of treatment outcome in classical Hodgkin's lymphoma: A retrospective, European, multicentre cohort study. Lancet Haematol 2016;3:e467-e479.

19. Ganesan P, Dhanushkodi M, Ganesan TS, Radhakrishnan V, Kannan K, Sundersingh S, et al. Prognostic utility of the IPS 3 score for predicting outcomes in advanced Hodgkin lymphoma. Clin Lymphoma Myeloma Leuk 2019;19:116-22.

20. Seshachalam A, Karpurmath SV, Rathnam K, Raman SG, Janarthinakani M, Prasad K, et al. Does interim PET scan after 2 cycles of ABVD predict outcome in Hodgkin lymphoma? Real-world evidence. J Glob Oncol 2019;5:1-3.

This is an open access journal, and articles are distributed under the terms of the Creative Commons Attribution-NonCommercial-ShareAlike 4.0 License, which allows others to remix, tweak, and build upon the work non-commercially, as long as appropriate credit is given and the new creations are licensed under the identical terms.

\begin{tabular}{|l|l|}
\hline \multicolumn{2}{|c|}{ Access this article online } \\
\hline Quick Response Code: & Website: \\
& www.ijmpo.org \\
\cline { 2 - 2 } & DOI: \\
\hline
\end{tabular}

How to cite this article: Ganesan P. Interim-response-adapted therapy in advanced Hodgkin's lymphoma: Current status. Indian J Med Paediatr Oncol 2019;40:566-9. 